\title{
Effect of Multiple Passes on Microstructural and Mechanical Properties of Surface Composite Al 2024/SiC Produced by Friction Stir Processing
}

\author{
Ashish Kumar Srivastava ${ }^{1 *}$, Nagendra Kumar Maurya ${ }^{1}$, Manish Maurya $^{2}$, Shashi Prakash Dwivedi ${ }^{1}$, Ambuj Saxena $^{1}$ \\ ${ }^{1}$ Department of Mechanical Engineering, G L Bajaj Institute of Technology and Management, Greater Noida 201308, India \\ ${ }^{2}$ Department of Mechanical Engineering, Accurate Institute of Management and Technology, Greater Noida 201308, India
}

Corresponding Author Email: ashish.srivastava@glbitm.ac.in

https://doi.org/10.18280/acsm.440608

Received: 13 April 2020

Accepted: 20 October 2020

\section{Keywords:}

Al2024 alloy, friction stir processing, Rockwell hardness test, tensile strength, nano indentation

\begin{abstract}
The application range in defense, aerospace and automotive sectors have enabled aluminium metal matrix composites to emerge in different technological fields due to enhanced micro structural and mechanical characteristics. In the present study, friction stir processing is used to fabricate $\mathrm{Al} 2024 / \mathrm{SiC}$ composite with one, two and three passes of the cylindrical tool. Optical microscopy and scanning electronic microscope (SEM) were used to validate the processed sample and to justify the morphological aspects. Energy dispersive spectroscopy (EDS) analysis has also performed to confirm the presence of $\mathrm{SiC}$ particles in the composite. It also includes the analysis of mechanical properties such as tensile strength, Rockwell hardness test and nanoindentation to characterize the prepared samples. Improvement in tensile strength with a maximum of $443 \mathrm{MPa}$, the hardness of $121 \mathrm{HRB}$ and nanoindentation of the specimen was depicted through the mechanical tests.
\end{abstract}

\section{INTRODUCTION}

In the present era, the use of composite material is in huge demand due to their lightweight, high tensile strength, hardness and less wear resistance in automotive, defense artillery and aircraft industries [1]. Aluminum matrix composites (AMCs) reinforced with various ceramic particles have been developed as a capable material to be used in the industries, due to their superior mechanical and tribological properties as compared to aluminium alloys. $\mathrm{SiC}$ particles tend to form strong bonding between with the aluminium alloy [2]. The limitation of traditional stir casting method is eliminated by solid metallurgical route i.e. friction stir processing technique (FSP) [3]. Various researchers have reported that it was feasible to prepare AMCs reinforced with $\mathrm{SiC}$ content. However, stir-cast $\mathrm{SiC}$ reinforced composites have several defects like porosity [4], accumulation of reinforced particles and development of brittle intermetallic resulted to interfacial reactions between the aluminium and $\mathrm{SiC}$ content were stated in the stir casting technique [5]. These defects have reduced the mechanical properties of the prepared composites during service. Uniform distribution of $\mathrm{SiC}$ particles is required to attain the improved mechanical properties with the best suited performance [6]. The interfacial bonding formed between the reinforced particles and the alloy was affected by the reaction products. Strong interfacial bonding is required between the reinforced particles and the alloy to affect the load-bearing capacity of the AMCs. Stir casting is widely accepted for preparing $\mathrm{Al} / \mathrm{SiC}$ composites [7]. However, preheating of $\mathrm{SiC}$ particles with the addition of $\mathrm{Mg}$ had improved the wettability of $\mathrm{SiC}$ particles [8]. Thus, progress in manufacturing techniques is important to fabricate AMCs and widen its applications.

Friction stir processing (FSP) has been developed as a solid- state metallurgical route to fabricate surface and bulk AMCs [9]. In FSP, a groove is cut along the transverse direction in the aluminium alloy. The groove is filled with ceramic particles. The non-consumable tool is rotated in the ceramic filled zone. The heat generated between the tool and the ceramic filled zone tends the plastic flow of reinforcement in the aluminium alloy. Grain refinement was observed in the stirred zone [10]. Thus, the composite is prepared by the movement of the tool and the applied axial load [11]. FSP has been fruitfully useful to create AMCs reinforced with $\mathrm{Al}_{2} \mathrm{O}_{3}$ [12], $\mathrm{SiO}_{2}$ [13], TiC [14], $\mathrm{B}_{4} \mathrm{C}$ [15], Ni [16], and NiTi [17]. Sharma et al. [18], Ghanbari et al. [19], Kurtyka et al. [20], Rathee et al. [21, 22] and Kumar et al. [23] have successfully incorporated $\mathrm{SiC}$ particles into the aluminum alloy to produce AMC's by using FSP technique. Thus, the purpose of this research work is to fabricate $\mathrm{SiC}$ reinforced composite using FSP and evaluate the mechanical and wear properties of FSPed Al 2024/SiC composite.

\section{MATERIALS AND METHOD}

Commercially available, Al2024 alloy plates were used in this research work. The chemical composition of Al 2024 alloy is given in Table 1 [24]. The dimensions of the plates taken were $100 \mathrm{~mm}$ x $50 \mathrm{~mm} \times 10 \mathrm{~mm}$. A groove of $1 \mathrm{~mm}$ width and $3 \mathrm{~mm}$ depth was made in the Al 2024 plate with the help of a vertical milling machine. The width of the groove was kept constant in four levels to produce 15 vol. $\%$ of SiC content and the number of passes i.e. $0,1,2$ and 3 were varied in this investigation. The groove was filled with $\mathrm{SiC}$ a particle of 25 to $30 \mu \mathrm{m}$. FSP was performed on a vertical milling machine. $\mathrm{HCHCr}$ steel tool was used for stirring purpose. Figure 1 shows the development of composite by FSP. The layout of 
the FSP tool along with the process is shown in Figure 2. Figure 3 shows the setup of the FSP used in the experiment. In the establishment of FSP, HCHCr tool without a pin was taken for capping operation to avoid $\mathrm{SiC}$ particles from absconding. The machine and FSP tool parameters are shown in Table 2.

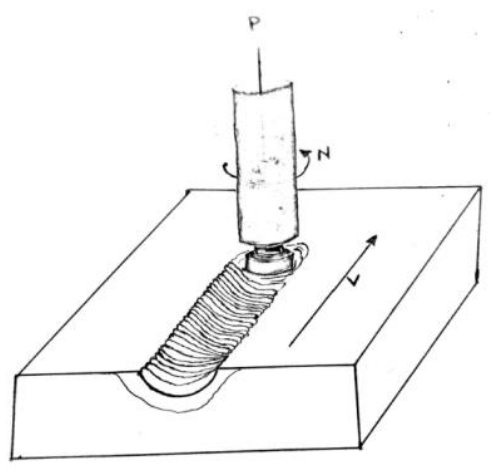

Figure 1. Development of composite by Friction Stir Processing

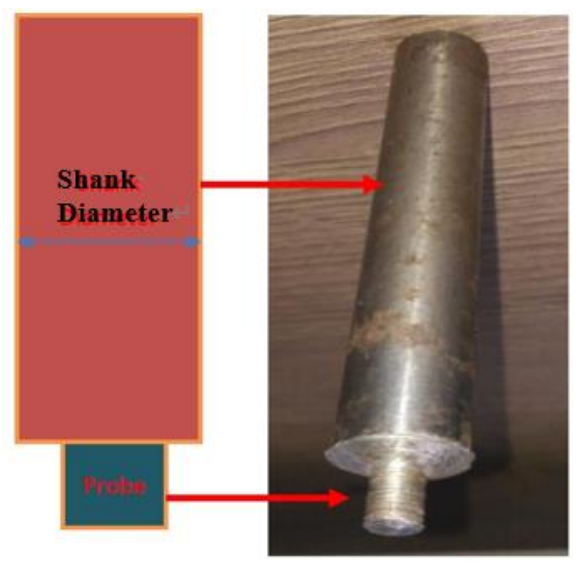

Figure 2. Layout of FSP tool and physical image of the tool used for the experiments

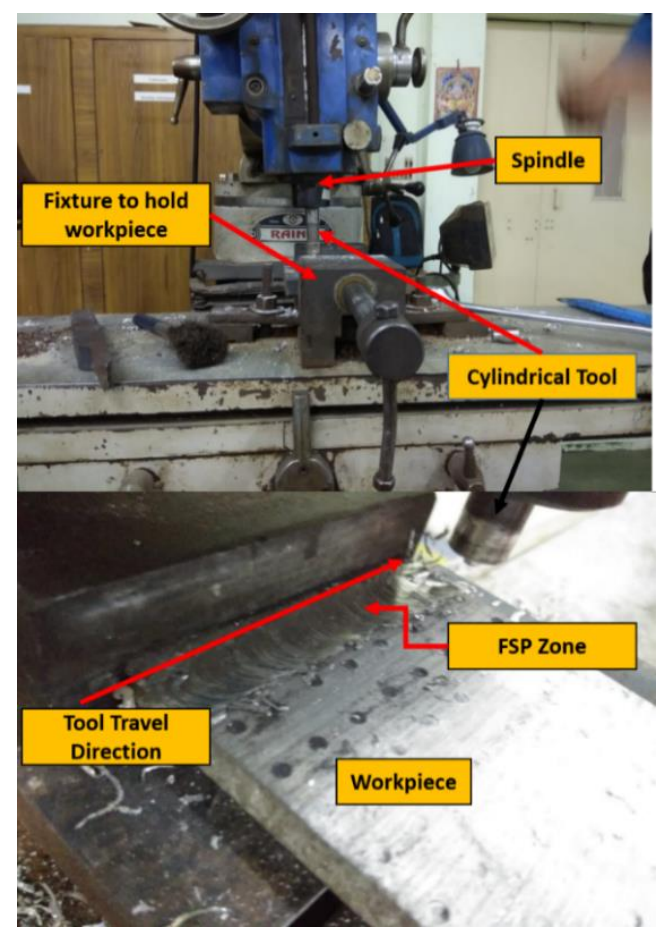

Figure 3. FSP setup
Table 1. Chemical composition of Al 2024 alloy [24]

\begin{tabular}{lllllllll}
\hline Si & Fe & Cu & Mn & Mg & Zn & Cr & Ti & Al \\
\hline 0.1 & 0.3 & 4.4 & 0.5 & 1.5 & 0.05 & 0.01 & 0.01 & Bal \\
\hline
\end{tabular}

Table 2. Process parameters used in the fabrication of $\mathrm{Al}$ 2024/SiC composite

\begin{tabular}{ccc}
\hline Sr. No. & Process Parameters & Values \\
\hline 1 & Rotational Speed $(\mathrm{rpm})$ & 1,000 \\
2 & Transverse Speed $(\mathrm{mm} / \mathrm{min})$ & 25 \\
3 & Tool Tilt Angle $\left(^{\circ}\right)$ & 0 \\
4 & Pin Profile of Tool & Cylindrical \\
5 & Shoulder Diameter $(\mathrm{mm})$ & 18 \\
6 & Pin Diameter $(\mathrm{mm})$ & 6 \\
7 & Pin Length $(\mathrm{mm})$ & 2.5 \\
\hline
\end{tabular}

\section{RESULTS AND DISCUSSION}

Friction stir processing of $\mathrm{Al} 2024 / \mathrm{SiC}$ surface composite has been completed. Figure 4 shows the raw plate and processed plate of Al2024. In the physical observation, a lot of tool marks in circular form has been shown on the processed surface. Few surface defects such as misrun, small blowholes are also seen which is attributed to the inefficient heat generation during the processing.

To conduct the micro structural observations, samples have been prepared as per ASTM E3-95 standard to conduct optical microscopy test. The FSP samples were polished and etched by using Keller's reagent to observe the microstructure. The test has been carried out by Leica-DMI3000 M inverted optical microscope. The results of optical microscopy are shown in Figure 5. It is clear from the image that homogeneous mixing of reinforced particles in the base metal of Al 2024 alloy is observed. At some point, there was less heat generation and particles of $\mathrm{SiC}$ remain as of bigger size. This was possible due to due to ineffectiveness of mixing of reinforced content. This can be reduced by creating turbulence and increasing the rotational speed of tool in the transverse direction.

Scanning Electronic Microscope was used to analyze the micro structural features in the friction stir zone (FSZ) along the transverse direction. Figure 6 shows the SEM images of FSZ, having three number of passes at $3 \mu \mathrm{m}$. SEM results confirm the presence of SiC particles in the stirred zone. The morphological imagination shows some minor defects such as micro-holes, blow holes etc. A similar type of result was obtained by Ghanbari et al. [19]. Misruns are also observed at some places which are due to the reduced heating effect which is generated due to frictional force.

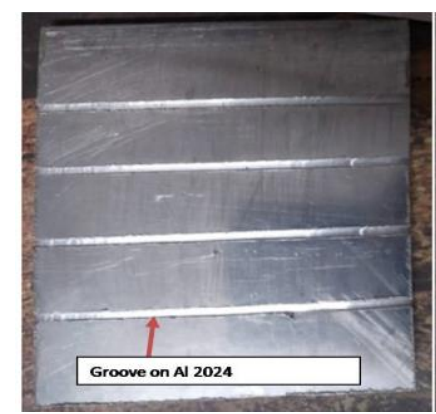

(a)

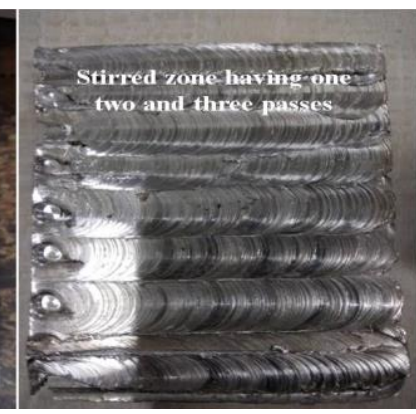

(b)
Figure 4. (a) Raw Material with groove (b) FSPed Al $2024 / \mathrm{SiC}$

Composite having one, two and three number of passes 


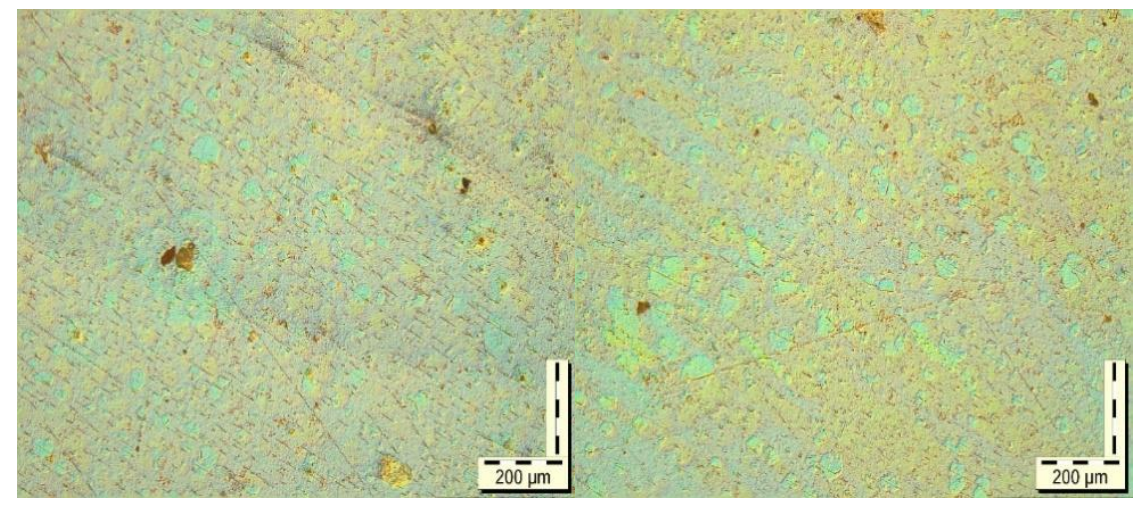

Figure 5. Microscopic images of the processed sample having three number of passes

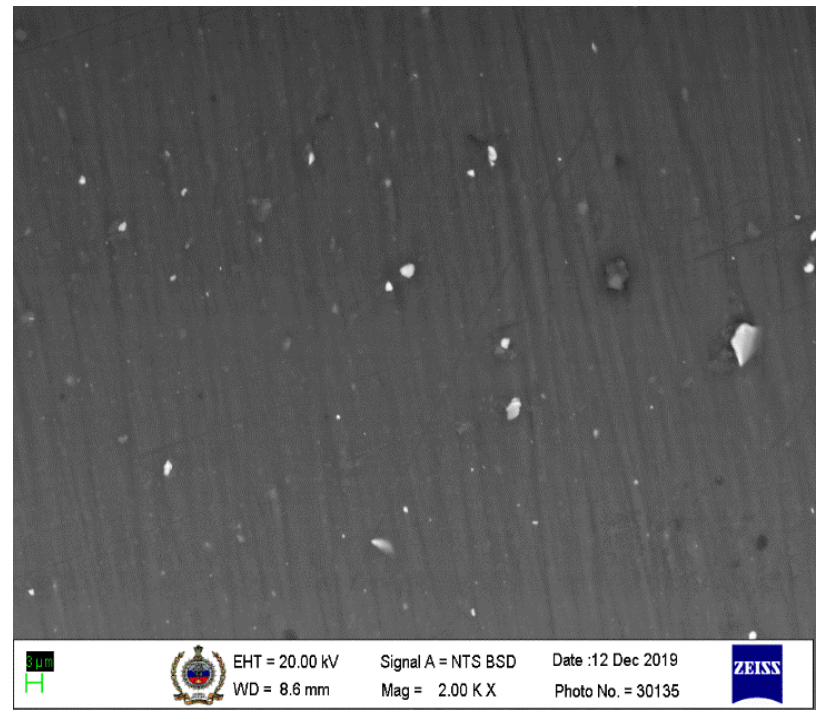

Figure 6. SEM image of FSZ, having three number of passes

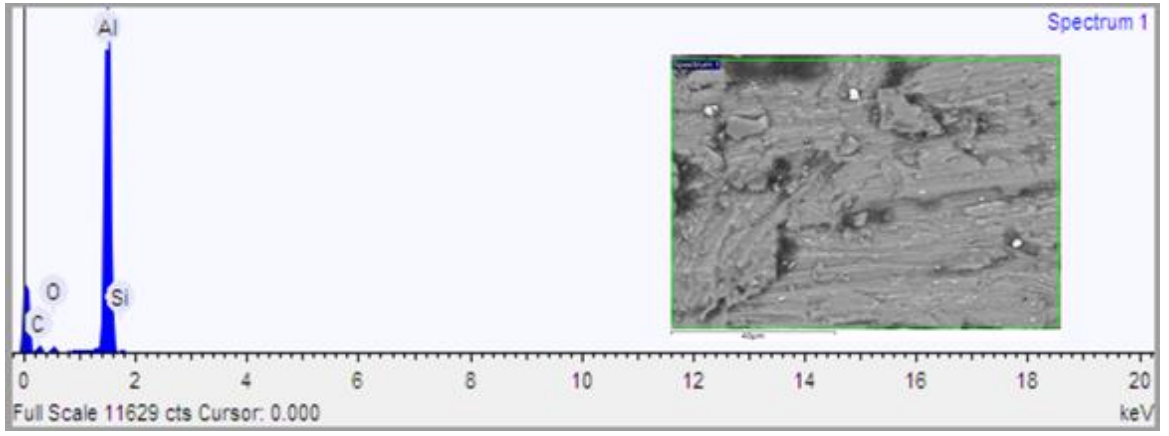

Figure 7. EDS of FSZ, having three passes

Al2024/SiC surface composite was also investigated by EDS (Energy-dispersive X-ray spectroscopy). Figure 7 shows the EDS of FSZ, having three number of passes. The acquisition conditions were taken at an acquisition time of $60.8 \mathrm{~s}$ and $15 \mathrm{kV}$ of accelerating voltage. EDS analysis depicts the mixing between $\mathrm{SiC}$ and $\mathrm{Al} 2024$ alloy. It confirms the presence of $\mathrm{SiC}$ particles into the processed sample.

The tensile test has been carried out by Universal testing machine of capacity ranging from $10 \mathrm{~N}$ to $10 \mathrm{KN}$. Figure 8 shows the sample for tensile testing and testing zone. The test has been carried out on all type of samples along with the raw sample to evaluate the trend of the tensile strength. Figure 9 shows the tensile strength of single, two and three tool pass surface composites. It has been observed from the graph that increasing the number of the pass, decreases the tensile strength. The maximum tensile strength of $443 \mathrm{MPa}$ is obtained in the single tool pass to mix SiC particles into the matrix alloy. While increasing the tool passes it decreases by $54 \mathrm{MPa}$ from the maximum value. It is because at the increasing number of pass the formation of surface defects was also increased which tends to lower the strength of the composites

Rockwell hardness test was performed on the prepared samples. Figure 10 shows the hardness of one, two and three pass composites. From the accomplished experimental result obtained from Figure 10, it is concluded that the hardness of single-pass FSPed Al 2024/SiC composite had got maximum hardness (121 HRB) than two or three passes FSPed composite or Al 2024 alloy. The similar trend of hardness was observed along both sides of the centerline in FSPed zone. This might 
be possible due to uniform distribution of hard $\mathrm{SiC}$ particles embedded in the stirred zone. FSP had refined the grain size of composite and had enhanced the surface hardness of singlepass FSPed Al 2024/SiC composite. Improvement in surface hardness was also observed in similar work $[25,26]$. The reason behind this may be the accumulation of $\mathrm{SiC}$ content in the retreating side. FSP tool was unable to move $\mathrm{SiC}$ content in the advancing side.

Nanoindentation test was evaluated on the prepared samples. It is evaluated at $500 \mathrm{gm}$ of load applied for $15 \mathrm{~s}$ at various locations in the specimens. Figure 11 shows the graph between load and displacement. It may be concluded from experimental results that displacement is found increases with the increased number of passes. This was possible because the heat generated between the FSP tool and the specimen was sufficient to plasticize the flow of $\mathrm{SiC}$ content. The tremendous dispersal of $\mathrm{SiC}$ content obstructs motion of disturbances. SiC content had increased the dislocation density of Al2024/SiC composite as compared to Al 2024 alloy.

Dislocations were formed due to the thermal mismatch between the Al2024 matrix and the SiC content. Meanwhile, the difference in thermal contraction between Al 2024 matrix and the $\mathrm{SiC}$ content had produced the quench hardening effect. By Hall-Petch relationship, it may be concluded that the grain size will influence the mechanical characteristics of the metallic materials. The grain size of the Al 2024/SiC composite is smaller as compared to the matrix due to grain refinement of the quartz particle. The fine grains result in increased microhardness. From Figure 11, it may be concluded that single-pass FSPed composite has maximum displacement and was improved as compared to two or three pass FSPed Al2024/SiC composite or Al2024 alloy, a similar study was also reported by Abreu et al. [26].

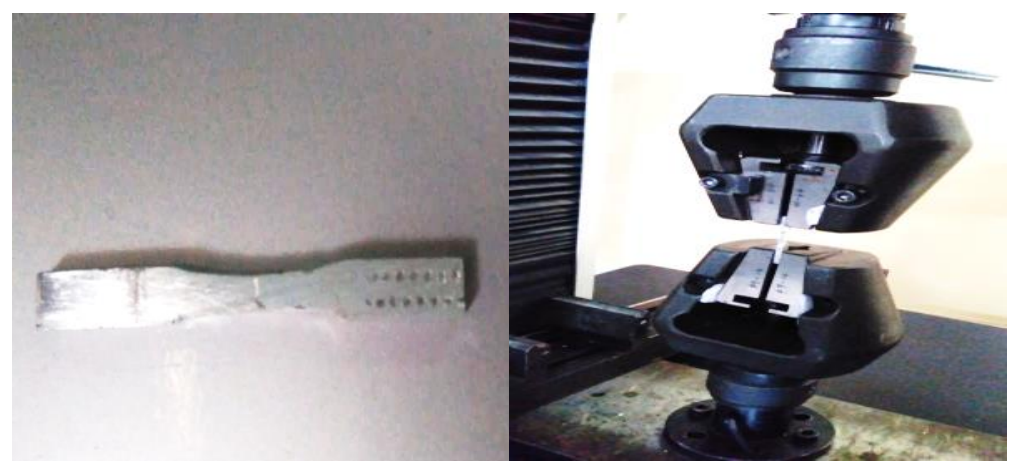

Figure 8. Sample tensile testing on UTM

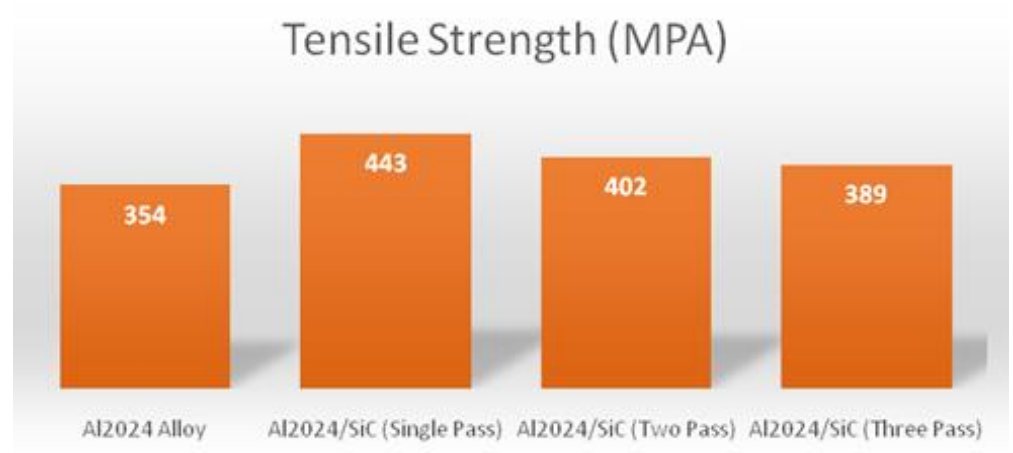

Figure 9. Tensile strength of A12024/SiC surface composite having single, two and three tool passes

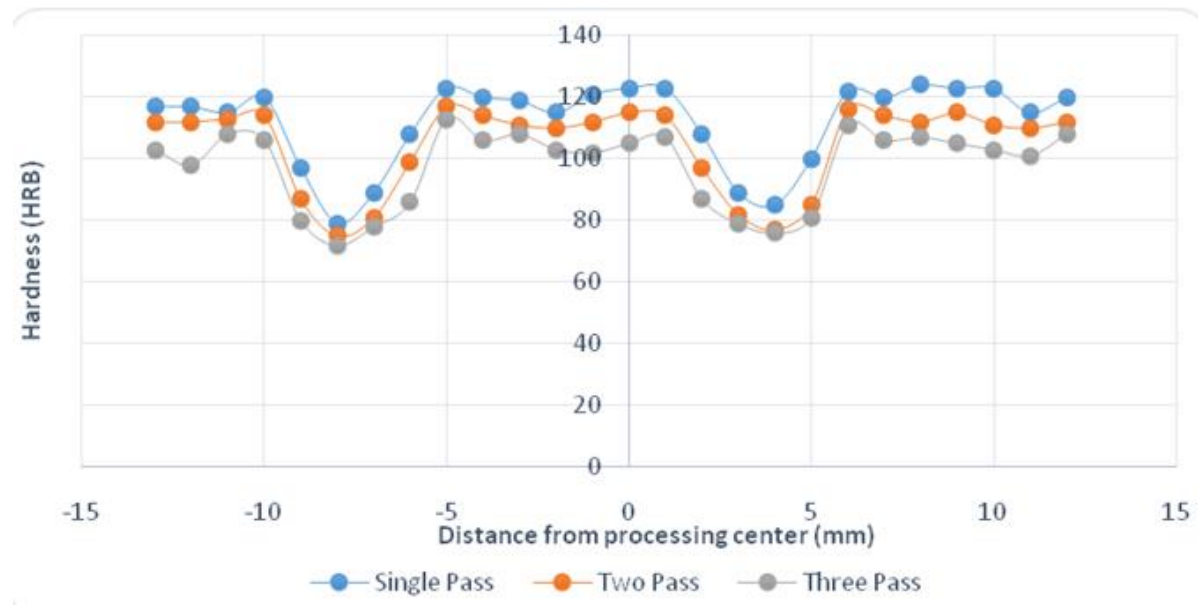

Figure 10. Rockwell hardness profile of the prepared composite 


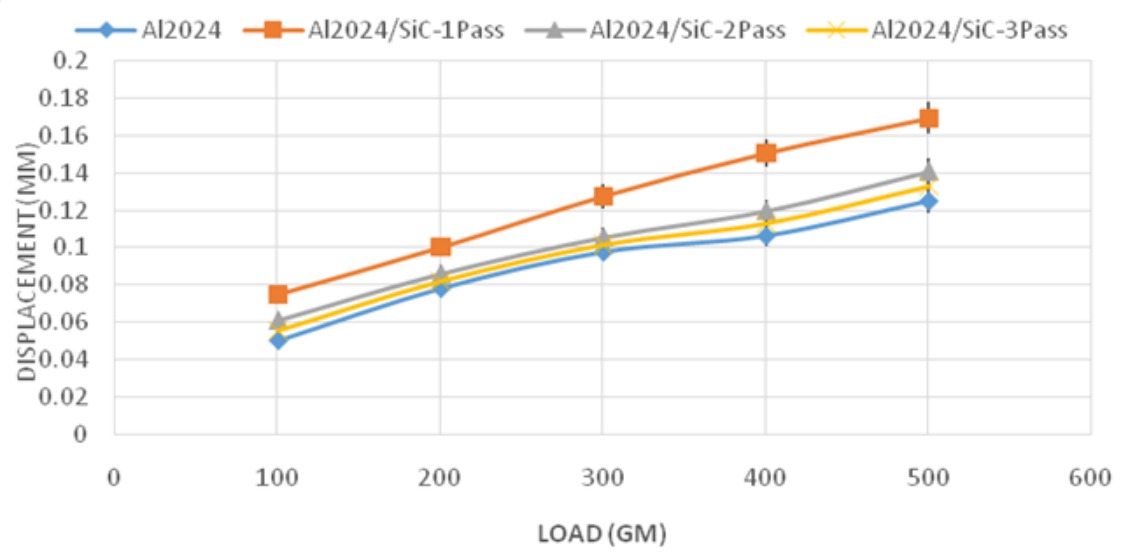

Figure 11. Displacement V/S Load graph

\section{CONCLUSIONS}

The Al2024/SiC composite was well developed via FSP technique. The effect of the number of passes on microstructure, hardness, and indentation was evaluated. The results concluded from the conducted experiments are as follows:

- Optical microscopic images and SEM results confirmed that $\mathrm{SiC}$ particles were uniformly distributed within the structure during the FSP method. Minor cluster formation was found in the composite. EDS results also revealed the $\mathrm{SiC}$ content in the friction stir processed zone.

- $\quad$ Maximum tensile strength of $443 \mathrm{MPa}$ was achieved at single-pass FSP while increasing the number of passes it decreases. At three pass the tensile strength is obtained $389 \mathrm{MPa}$.

- Rockwell hardness results had confirmed the improvement of hardness in the $\mathrm{Al} 2024 / \mathrm{SiC}$ composite. Single-pass FSPed Al 2024/SiC composite had got maximum hardness (121 HRB) than two or three passes FSPed composite or Al 2024 alloy. The similar trend of hardness was observed along both sides of the centerline in FSPed zone.

- $\quad$ Micro hardness test confirmed that the improvement in micro hardness was observed in the Al2024/SiC composite. The maximum micro-hardness was obtained for single-pass composites.

FSP, efficient technology has developed the composite with excellent mechanical properties. Further investigation of properties is possible by the variation of groove shape, width or change in process parameters. FSP tool and its specifications had played a vital role in the experiment. The variation of tool parameters along with process parameters can give better results in further attempts while experimenting.

\section{REFERENCES}

[1] Maurya, M., Kumar, S., Bajpai, V., Maurya, N.K. (2020). Process parameters, development and applications of stir cast composite: A review. Materials Testing, 62(2): 196208. https://doi.org/10.3139/120.111472

[2] Dwivedi, S.P., Srivastava, A.K., Maurya, N.K., Sahu, R. (2020). Microstructure and mechanical behaviour of $\mathrm{Al} / \mathrm{SiC} /$ Agro-Waste RHA hybrid metal matrix composite.
Revue des Composites et des Matériaux Avancés-Journal of Composite and Advanced Materials, 30(1): 43-47. https://doi.org/10.18280/rcma.300107

[3] Srivastava, A.K., Singh, R.K., Kumar, S., Dwivedi, S.P., Maurya, N.K., Mishra, S. (2020). Development of duralumin alloy and its microstructural characterization by using grain refiner. Materials Today: Proceedings, 245(4): $877-880$. https://doi.org/10.1016/j.matpr.2019.12.027

[4] Maurya, M., Maurya, N.K., Bajpai, V. (2019). Effect of $\mathrm{SiC}$ reinforced particle parameters in the development of aluminium based metal matrix composite. Evergreen Joint Journal of Novel Carbon Resource Sciences \& Green Asia Strategy, 6(3): 200-206. https://doi.org/10.5109/2349295

[5] Srivastava, A.K., Gupta, Y., Patel, S., Tiwari, S.K., Pandey, S. (2019). Metal matrix composites-a review on synthesis and characterization. IOP Conf. Series: Materials Science and Engineering, 691: 012077. https://doi.org/10.1088/1757-899X/691/1/012077

[6] Srivastava, A.K., Dixit, A.R., Tiwari, S. (2016). A review on the intensification of metal matrix composites and its nonconventional machining. Science and Engineering of Composite Materials, 25(2): 213-228. https://doi.org/10.1515/secm-2015-0287

[7] Maurya, N.K., Maurya, M., Srivastava, A.K., Dwivedi, S.P., Kumar, A., Chauhan, S. (2019). Investigation of mechanical properties of $\mathrm{Al} 6061 / \mathrm{SiC}$ composite prepared through stir casting technique. Materials Today: Proceedings, 25(4): 755-758. https://doi.org/10.1016/j.matpr.2019.09.003

[8] Srivastava, A., Nag, A., Dixit, A., Hloch, S., Tiwari, S., Scucka, J., Pachauri, P. (2019). Surface integrity in wireEDM tangential turning of in situ hybrid metal matrix composite A359/B4C/Al ${ }_{2} \mathrm{O}_{3}$. Science and Engineering of Composite Materials, 26(1): 122-133. https://doi.org/10.1515/secm-2017-0391

[9] Kumar, S., Srivastava, A.K., Singh, R.K., Dwivedi, S.P. (2019). Experimental study on hardness and fatigue behavior in joining of AA5083 and AA6063 by friction stir welding, Materials Today: Proceedings, 25(4): 646648. https://doi.org/10.1016/j.matpr.2019.07.535

[10] Zhao, Y.D., Ding, Z.M., Shen, C.B., Chen, Y. (2016). Interfacial microstructure and properties of aluminiummagnesium AZ31Bmulti-pass friction stir processed composite plate. Materials \& Design, 94: 240-252. 
https://doi.org/10.1016/j.matdes.2016.01.047

[11] Sharma, V., Prakash, U., Kumar, B.V.M. (2015). Microstructural and mechanical characteristics ofAA2014/SiC surface composite fabricated by frictionstir processing. Materials Today: Proceedings, 2(4-5): 2666-2670. https://doi.org/10.1016/j.matpr.2015.07.229

[12] Yang, K., Li, W.Y., Niu, P.L., Yang, X.W., Xu, Y.X. (2018). Cold sprayed $\mathrm{AA} 2024 / \mathrm{Al}_{2} \mathrm{O}_{3}$ metal matrix composites improved by friction stir processing: Microstructure characterization, mechanical performance and strengthening mechanisms. Journal of Alloys Compounds, 736: 115-123. https://doi.org/10.1016/j.jallcom.2017.11.132

[13] Abraham, J.S., Rao Madane, C.S., Dinaharan, I., Baruch, J.L. (2016). Development of quartz particulate reinforced AA6063 aluminum matrix composites via friction stir processing. Journal of Asian Ceramic Societies, 4(4): 381-389. https://doi.org/10.1016/j.jascer.2016.08.001

[14] Thangarasu, A., Murugan, N., Dinaharan, I., Vijay, S.J. (2014). Influence of transverse speed on microstructure and mechanical properties of AA 6082-TiC surface composite fabricated by friction stir processing. Procedia Materials Science, 5: 2115-2121. https://doi.org/10.1016/j.mspro.2014.07.547

[15] Yuvaraj, N., Aravindan, S., Vipin. (2015). Fabrication of Al5083/B4C surface composite by friction stir processing and its tribological characterization. Journal of Materials Research and Technology, 4(4): 398-410. https://doi.org/10.1016/j.jmrt.2015.02.006

[16] Bauri, R., Janaki Ram, G.D., Yadav, D., Shyam Kumar, C.N. (2015). Effect of process parameters and tool geometry on the fabrication of Ni particles reinforced $5083 \mathrm{Al}$ composite by frictionstir processing. Materials Today: Proceedings, 2(4-5): 3203-3211. https://doi.org/10.1016/j.matpr.2015.07.115

[17] Ni, D.R., Wang, J.J., Ma, Z.Y. (2016). Shape memory effect, thermal expansion and damping property of friction stir processed NiTip/Al composite. Journal of Materials Science \& Technology, 32(2): 162-166. https://doi.org/10.1016/j.jmst.2015.12.013

[18] Sharma, V., Prakash, U., Kumar, B.V.M. (2015). Microstructural and mechanical characteristics ofAA2014/SiC surface composite fabricated by friction stir processing. Materials Today: Proceedings, 2(4-5): 2666-2670. https://doi.org/10.1016/j.matpr.2015.07.229

[19] Ghanbari, D., KasiriAsgarani, M., Amini, K., Gharavi, F. (2017). Influence of heat treatment on mechanical properties and microstructure of the Al2024/SiC composite produced by multi-pass friction stir processing. Measurement, 104: 151-158. https://doi.org/10.1016/j.measurement.2017.03.024

[20] Kurtyka, P., Rylko, N., Tokarski, T., Wójcicka, A., Pietras, A. (2015). Cast aluminium matrix composites modified with using FSP process-changing the structure and mechanical properties. Composite Structures, 133: 959-967.

https://doi.org/10.1016/j.compstruct.2015.07.122

[21] Rathee, S., Maheshwari, S., Noor Siddiquee, A., Srivastava, M., Sharma, S.K. (2015). Process parameters optimization for enhanced microhardness of AA 6061/SiC surface composites fabricated via friction stir processing (FSP). Materials Today: Proceedings, 3(10): 4151-4156. https://doi.org/10.1016/j.matpr.2016.11.089

[22] Rathee, S., Maheshwari, S., Siddiquee, A.N., Srivastava, M. (2017). Investigating effects of groove dimensions on microstructure and mechanical properties of AA6063/SiC surface composites produced by friction stir processing. Transactions of the Indian Institute of Metals, 70: 809-816. https://doi.org/10.1007/s12666017-1060-7

[23] Jain, V.K.S., Muhammed, P.M., Muthukumaran, S., Kumaresh Babu, S.P. (2018). Microstructure and mechanical and sliding wear behaviour of AA5083$\mathrm{B} 4 \mathrm{C} / \mathrm{SiC} / \mathrm{TiC}$ surface composites fabricated using friction stir processing. Transactions of the Indian Institute of Metals, 71: 1519-1529. https://doi.org/10.1007/s12666-018-1287-y

[24] Hosseinzadeh, A., Yapici, G.G. (2018). High temperature characteristics of $\mathrm{Al} 2024 / \mathrm{SiC}$ metal matrix composite fabricated by friction stir processing. Materials Science \& Engineering A, 731: 487-494. https://doi.org/10.1016/j.msea.2018.06.077

[25] Sharma, V., Prakash, U., Manoj Kumar, B.V. (2015). Microstructural and mechanical characteristics of AA2014/SiC surface composite fabricated by friction stir processing. Materials Today: Proceedings, 2(4-5): 26662670. https://doi.org/10.1016/j.matpr.2015.07.229

[26] Abreu, C.M., Acuna, R., Cabeza, M., Cristobal, M.J., Merino, P., Verdera, D. (2017). Microstructure and mechanical properties of $\mathrm{Al} / \mathrm{SiC}$ composite surface layer produced by friction stir processing. Ciência \& Tecnologia dos Materiais, 29(1): e82-e86. https://doi.org/10.1016/j.ctmat.2016.07.001 